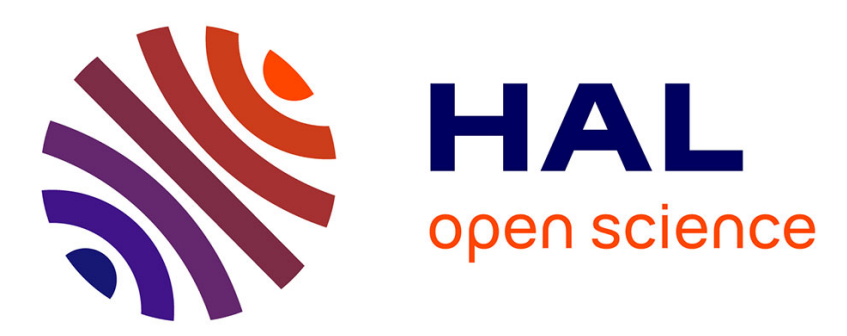

\title{
Chromatin domains in space and their functional implications
}

Frederic Pontvianne, Chang Liu

\section{To cite this version:}

Frederic Pontvianne, Chang Liu. Chromatin domains in space and their functional implications.

Current Opinion in Plant Biology, 2020, 2020, pp.1 - 10. 10.1016/j.pbi.2019.11.005 . hal-02428536

\section{HAL Id: hal-02428536 \\ https://hal-univ-perp.archives-ouvertes.fr/hal-02428536}

Submitted on 6 Jan 2020

HAL is a multi-disciplinary open access archive for the deposit and dissemination of scientific research documents, whether they are published or not. The documents may come from teaching and research institutions in France or abroad, or from public or private research centers.
L'archive ouverte pluridisciplinaire HAL, est destinée au dépôt et à la diffusion de documents scientifiques de niveau recherche, publiés ou non, émanant des établissements d'enseignement et de recherche français ou étrangers, des laboratoires publics ou privés. 
1 Chromatin domains in space and their functional implications

2

3 Frédéric Pontvianne ${ }^{1,2}$ and Chang Liu ${ }^{3}$

4

5

$6 \quad{ }^{1}$ CNRS, Laboratoire Génome et Développement des Plantes (LGDP); Université de

7 Perpignan Via Domitia, LGDP, UMR 5096, Perpignan 66860, France

8 'UPVD, Laboratoire Génome et Développement des Plantes (LGDP); Université de

9 Perpignan Via Domitia, LGDP, UMR 5096, Perpignan 66860, France

$10{ }^{3}$ Center for Plant Molecular Biology (ZMBP), University of Tübingen, Auf der

11 Morgenstelle 32, Tübingen 72076, Germany

12

13

14 Correspondence:

15 frederic.pontvianne@univ-perp.fr; ORCID ID: 0000-0002-2913-4104

16 chang.liu@zmbp.uni-tuebingen.de ; ORCID ID: 0000-0003-2859-4288 


\section{Abstract}

18 Genome organization exhibits functional compartmentalization. Several factors, 19 including epigenetic modifications, transcription factors, chromatin remodelers, and 20 RNAs shape chromatin domains and the three-dimensional genome organization. 21 Various types of chromatin domains with distinct epigenetic and spatial features exhibit different transcriptional activities. As part of the efforts to better understand plant functional genomics, over the past a few years, spatial distribution patterns of plant chromatin domains have been brought to light. In this review, we discuss chromatin domains associated with the nuclear periphery and the nucleolus, as well as chromatin domains staying in proximity and showing physical interactions. The functional implication of these domains is discussed, with a particular focus on the transcriptional regulation and replication timing. Finally, from a biophysical point of view, we discuss potential roles of liquid-liquid phase separation in plant nuclei in the genesis and maintenance of spatial chromatin domains.

\section{Introduction}

In eukaryotes, the nuclear DNA is wrapped around histone octamers to form the chromatin. Chromatin is subject to extensive modifications including DNA methylation and post-translational histone modifications [1]. These modifications, also named epigenetic marks, form the epigenome. To understand the three-dimensional genome organization in relation to local epigenetic states, it is also necessary to consider the subnuclear components that include (i) nuclear bodies such as the nucleolus, nuclear speckles and Cajal bodies, as well as (ii) nuclear pores and the nuclear periphery $[2,3]$. In mammalian cells, large chromatin regions associate at the nuclear periphery with a network composed of lamin fibers are named Lamina-associated domains (LADs) [4]. Some chromatin domains also associate with the nucleolar periphery, which actually belongs to nucleolus, and are named nucleolus-associated chromatin domains (NADs) $[5,6]$. Besides, mammal genomes predominantly form thousands of self-organizing chromatin domains known as topologically associated domains (TADs), which are relatively insulated from one another [7]. In plants, chromatin domains comparable to animal LADs, NADs, and TADs have been found. It should be pointed out here that our knowledge of these plant chromatin domains is still preliminary, at the moment, 
51 Genome organization is also highly dynamic, and is subjected to changes according

52 to the cell cycle progression, developmental transition like commencing 53 photomorphogenesis or flowering, and external cues [8]. For instance, in the presence 54 of light, as a result of progressive compaction of heterochromatin, nuclei in germinating 55 Arabidopsis seedlings produce chromocenters, which appear as large, bright spots 56 upon stained with DAPI [9]. How are chromatin organization patterns, with a certain 57 degree of orderliness in space, formed? For long, affinity between different molecules 58 was thought to be the most important force determining how they are distributed in 59 space. A protein can diffuse through the nucleus and thanks to its affinity and specificity 60 to other factors, this protein might be retained longer in some nuclear compartment 61 than others [10]. Recent advances also revealed the potential role of proteins 62 possessing intrinsically disordered regions (IDRs) in the establishment and 63 maintenance of nuclear compartments [11,12]. In this short review, we refer to plant 64 "chromatin domains" as chromatin regions identified with methods concerning three65 dimensional (3D) chromatin organization and positioning. With a focus on the 66 demarcation and functionality of selected plant chromatin domains, we summarize and 67 discuss recent progress in plant three-dimensional (3D) genomics.

\section{Identification of plant chromatin domains from a 3D perspective}

70 Functional annotation of plant long-range cis-regulatory elements

71 Besides identifying functional chromatin domains via acquiring a detailed picture of 72 epigenomic and structural features (e.g., by using ChIP-seq and ATAC-seq 73 approaches), investigating 3D chromatin conformation provides complementary 74 structural and functional insights into them. In particular, this information is crucial for 75 identifying gene(s) regulated by a given candidate enhancer element and vice versa. 76 In the past decade, $\mathrm{Hi}-\mathrm{C}$ (Chromosome Conformation Capture coupled with High 77 Throughput Sequencing) has become the most widely used approach to study physical 78 chromatin contact networks in 3D $[13,14]$. Hi-C approaches have been applied to a 79 variety of plant species, from which both expected and surprising chromatin 80 organization patterns as opposed to animals have been discovered (reviewed recently 81 in [15-17]). Similar to those in animals, chromatin compartmentalization and local 82 chromatin insulation have been observed in plants, implying that they can prevent 
83 chromatin regions from freely interacting with one another. Such spatial constraints of 84 chromatin contacts are part of how distal cis-regulatory elements regulate expression of their target genes via establishing specific long-range physical interactions. Over the past few years, there have been increasing efforts in systematically identifying cisregulatory elements and enhancers in various plant species, such as Arabidopsis [1822], rice [22-24], tomato [22,25], maize [26], and wheat [27]. These approaches are based on searching for chromatin regions with local structural and epigenetic features similar to those in animal genomes. A challenge downstream of this approach is how to correctly annotate these potential regulatory elements by assigning them to their target gene loci.

On the contrary, $\mathrm{Hi}-\mathrm{C}$ can provide researchers important information regarding chromatin domain interactions; however, Hi-C has limited sensitivity in systematically detecting chromatin loops, as it is financially costly to increase the sequencing depth of a genome-wide $\mathrm{Hi}-\mathrm{C}$ map to boost the statistical power of loop calling. Nonetheless, $\mathrm{Hi}-\mathrm{C}$ studies in Arabidopsis [28], rice [29], and cotton [30] show that chromatin regions involved in forming chromatin loops are enriched at gene promoters, reflecting the existence of extensive yet largely uncharted contacts between genes and their regulatory elements in plants. Compared to using $\mathrm{Hi}-\mathrm{C}$, one can better resolve spatial organization among chromatin domains with approaches that dedicate sequencing resource to genomic regions of interest. For instance, both the ChIA-PET (Chromatin Interaction Analysis by Paired-End Tag Sequencing) and HiChIP (Hi-C Chromatin Immunoprecipitation) methods aim to reveal chromatin interaction networks of regions associated with a defined chromatin mark or transcriptional regulator $[31,32]$. Recently, several studies using ChIA-PET unveiled chromatin interaction patterns associated expressed genes in maize and rice [33-35]. The two maize ChIA-PET studies by Li et al. [33] and Peng et al. [34] focused on chromatin domains with H3K4me3, H3K27ac, and RNA Pol2, which were hallmarks of active promoter, enhancer, and transcribed regions, respectively. Collectively, their work identified unprecedented networks of

111 promoter-enhancer and promoter-promoter interactions in maize, some of which were 112 well known as contributors of important agronomic traits. Likewise, a recent ChIA-PET 113 study of rice revealed physical interactions between many eQTLs (expression 114 Quantitative Trait Loci) and their target genes [35].

115 In summary, these work demonstrate the advantage of identifying and annotating 116 functional regulatory chromatin regions by integrating both one- and three-dimensional 117 genomic features. In our opinion, a combinatory strategy with two steps can be 
118 considered as a standard practice for functional annotation of regulatory elements in

119 a given plant genome. The first step involves identifying chromatin regions with

120 features of interest (e.g., epigenetic marks), and the second step involves using Hi-C-

121 related methods that explore their chromatin-chromatin interaction network.

123 Identifying plant LADs and NADs

124 Another way of annotating 3D chromatin domains is based on their localization in the

125 nucleus. In animals, active and repressed chromatin regions tend to be separated from

126 each other, and some areas in the nucleus, such as nuclear periphery and nucleolar

127 periphery, are enriched with repressed chromatin [36,37]. Recently, chromatin

128 domains preferentially localized at the nuclear and/or nucleolar periphery in

129 Arabidopsis have been identified (Figure 1a).

130 Arabidopsis perinuclear chromatin domains were initially identified with an artificial

131 system, which did not reveal direct interactions between the nuclear envelope and

132 these domains [38]. Nevertheless, these plant perinuclear chromatin domains were

133 enriched with various repressive marks (e.g., H3K27me3 and DNA methylation),

134 suggesting that the plant nuclear periphery was a compartment in favor of holding

135 repressed genes [38]. Later on, it was shown that some plant-specific nuclear lamin

136 candidate proteins, CROWDED NUCLEI (CRWN), were required to tether chromatin

137 to the nuclear periphery in Arabidopsis [39,40]. By using CRWN1 as bait, chromatin

138 domains bound by CRWN1 at the nuclear periphery (named plant LADs) were

139 identified with chromatin immunoprecipitation [39]. Pattern analyses of plant LADs

140 confirmed the previous conclusion that the plant nuclear periphery is a repressive

141 environment [39]. On the other hand, the identification of NADs was achieved by

142 isolating intact nucleoli $[41,42]$. In addition to ribosomal RNA loci, NADs are clearly

143 enriched with lowly expressed protein-coding genes, as well as inactive chromatin

144 marks and transposons [41]. Thus, plant LADs and NADs are both transcriptionally

145 inactive; however, as they are located in different nuclear compartments, the

146 respective silencing mechanisms might be different to a certain extent. For instance,

147 the silencing of NAD-genes might be due to preventing RNA polymerase II from being

148 associated with the nucleolus [43]. On the other hand, the plant lamin protein CRWN1

149 was shown to interact with PWWP INTERACTOR OF POLYCOMBS 1 (PWO1), which

150 associated with Polycomb-group proteins, suggesting the involvement of H3K27me3-

151 mediated transcriptional repression in LADs [44]. At the moment, research of plant 
152 LADs and NADs are still at an infant stage, as the knowledge of proteins required for 153 forming these chromatin domains is extremely limited. Also, it is not known how 154 variable plant LADs and NADs demarcations are across different cell types and growth 155 conditions. Given the highly dynamic nature of plant nuclei $[45,46]$, we envisage that 156 these plant chromatin domains possess a certain degree of flexibility, participating in 157 modulating 3D genome organization and transcriptional regulations.

158 A comparison between Arabidopsis LADs and NADs revealed that a tiny fraction of the 159 genome is enriched both at the nuclear periphery and the nucleolus [47]; notably, most 160 of these domains overlap with pericentromeric regions at chromosome 4 , and to a less 161 extent with those at chromosome 2 (Figure 1b). The occurrence of interchangeable 162 perinuclear and nucleolar chromatin domains has been found in animals before $[5,48]$.

163 A recent study of NADs identification in mouse embryonic fibroblast cells reported that 164 a small subset of NADs were also frequently associated with the nuclear lamina [49]. 165 These chromatin domains, shared by LADs and NADs (named "type I NADs"), 166 appeared to be more heterochromatic; while the other type of NADs ("type II NADs") 167 tend to be relatively promoting gene expression and enriched with developmentally 168 regulated genes [49]. We speculate that the chromatin domains shuffling between the 169 nuclear periphery and the nucleolus in plants might be functionally distinct from the 170 domains without such dual localization. For the Arabidopsis genome, it would also be 171 interesting to investigate whether these $L A D / N A D$ interchangeable regions are 172 involved in modulating dynamics of chromocenter (specifically chromosomes 2 and 4) 173 structures during plants' growth and development [50].

175 Functions of plant chromatin domains in 3D

176 In this section we discuss functional implications of the abovementioned chromatin 177 domains.

178 co-expression of genes

179 In an earlier Hi-C work by Dong and colleagues, tomato and maize genomes were 180 shown to form a large number of long-range chromatin loops linking interstitial active 181 chromatin regions [51], suggesting spatial clustering of expressed genes. Later on, the 182 interaction networks of maize active chromatin were revealed by two research groups 183 using the ChIA-PET method, and suggested a role for these physical interactions on 184 gene expression [33,34]. Albeit the datasets from these two teams are difficult to 
185 compare due to the use of different growth conditions, tissues types, and antibodies 186 (for ChIP) [33,34], three consensus patterns can be extracted. Firstly, a substantial

187 fraction of the identified chromatin loops connects gene loci; secondly, genes forming 188 long-range chromatin interactions tend to show higher expression levels than those 189 without; thirdly, gene pairs linked with chromatin loops tend to show co-expression. 190 Based on a recent rice ChIA-PET study, coordinated expression of active genes can 191 also be found among those connected by chromatin loops [35]. Together, these results 192 strongly suggest that active chromatin domains in plant nuclei can form extensive 193 physical contacts via chromatin interactions.

194 Earlier studies of gene expression in several plant species have pointed out that it is 195 common to observe co-expression between neighboring genes [52-55]. An 196 explanation of this phenomenon is that neighboring genes (especially those with 197 overlapping divergent promoters) share some common cis-regulatory elements. The 198 promoters of neighboring gene can also contact with one another via forming 199 chromatin loops. Most of the reported plant promoter-promoter interactions are 200 between physically linked loci in the genome [33,34]. Considering chromatin as a 201 polymer, due to distance-dependent stochastic contacts, it is known that nearby 202 genomic loci have much stronger contacts than do loci separated by large genomic 203 distances [56]. This correlates well with the fact that $\mathrm{Hi}-\mathrm{C}$ maps, regardless of species 204 and cell types, always display strong contacts around their diagonal lines (indicative of 205 interactions over short genomic distances). We speculate that stochastic contacts 206 among loci along the chromatin fibre, as a function of genomic distance, contribute 207 significantly to interactions between promoters and cis-elements. In addition, we also 208 speculate that transcriptional regulators are involved in forming these chromatin 209 contacts (Figure 1a) (see discussion in the next section). Together, the cooperative 210 interactions among multiple transcribed loci form a spatial domain of "transcriptional 211 ecosystem equilibrium" in the nucleus that fosters co-expression patterns [57]. Such 212 physical interactions among active chromatin could be a mechanism underlying co213 expression of metabolic genes residing close to each other (i.e., members belonging 214 to a gene cluster annotated in the linear genome) $[58,59]$.

\section{DNA replication timing}

217 Spatial chromatin domain distribution is not only associated with gene transcription 218 regulation, but also with other essential chromatin activities. As part of the cell cycle, 
219 DNA replication is a process by which genomic content is duplicated before a cell 220 enters mitosis. Interestingly, DNA replication timing across the genome is not 221 homogeneous, rather, it displays a correlation to local histone marks and 3D 222 chromosome structures [60]. In animals, euchromatin, which is localized in the nuclear 223 interior, is replicated earlier than perinuclear localized heterochromatin [60]. Similarly, 224 studies comparing chromatin regions with different replication timing patterns in maize 225 root tip nuclei showed that open chromatin and densely packed heterochromatin 226 domains tend to be duplicated in early and late $S$ phases, respectively $[61,62]$. The 227 same correlation was seen in Arabidopsis suspension cells, that repressed chromatin 228 were enriched in late replicated loci [63,64]. Further, live imaging of Arabidopsis 229 replisomes revealed their dynamic distribution in early and late S phase [65]. All these 230 observations suggest that plant DNA duplication happens in accordance with different 231 chromatin features (e.g., heterochromatin tends to be replicated late). As mentioned 232 above, Arabidopsis nuclei show enrichment of repressed chromatin regions at the 233 nuclear periphery and the nucleolus; therefore, it is expected that such chromatin 234 compartmentalization correlate with late/early replication patterns. Indeed, for 235 chromatin loci belonging to either LADs or NADs in Arabidopsis, they clearly show a 236 preference for being replicated in the last $S$ phase (Figure 2a, b). Interestingly, further 237 analyses on DNA replication origins with these chromatin domains reveal that the 238 distribution of leading nascent strands over LADs and NADs are different (Figure 2c, 239 d). Overall, among the nascent strands identified in a recent study [66], LADs overlap 240 more with those pointing inward; while NADs overlap more with those pointing 241 outward, suggesting that the replication of these two types of repressed chromatin 242 domains are regulated by different mechanisms. Recent work in mammals has led to 243 the identification of Early Replicating Control Elements (ERCEs) that play roles in 244 regulating both DNA replication timing and 3D chromatin organization [67]. Certainly, 245 it would be interesting to study if plants also have such a mechanism that integrates 246 DNA replication and chromatin organization. Many plant species can carry on 247 endoreduplication, which is a process doubling the nuclear genome in the absence of 248 mitosis [68]. As an extreme example, during tomato fruit development, the 249 endopolyploidy level of pericarp cells can reach $512 \mathrm{C}$ (C is the haploid DNA content; 250 and 512C means nine rounds of endoreduplication) [69]. So far, it is not known whether 251 the recurring DNA replication during endoreduplication cycle is accompanied with 252 changes in chromatin organization and epigenetic landscape. 
254 Liquid-liquid phase separation (LLPS) as a prominent biophysical process

255 implicated in arranging chromatin domains in 3D

256 Role of liquid-liquid phase separation in the nucleus

257 Nuclear sub-compartments are membrane-less organelles or condensates and are 258 characterized by liquid-phase properties. In that case, they are liquid-phase 259 compartments and remain separated from each other through liquid-liquid phase 260 separation (LLPS). LLPS form nuclear condensate or droplets, and are generated by 261 spontaneous nucleation of a given molecules resent at a high concentration. These 262 phenomenon participate in the creation of functional hubs that allow the enrichment of 263 factors required in a specific biological process such as mRNA biosynthesis or 264 ribosome biogenesis. Recent advances clearly demonstrated the implication of LLPS 265 in the establishment of non-membrane organelles in the nucleus [12]. Proteins with 266 intrinsically disordered regions (IDRs) play a crucial role in the genesis and 267 maintenance of phase-separated bodies. Recent work demonstrated that LLPS could 268 act at the scale of large chromatin domains (i.e TAD or NAD), at the scale of a 269 chromatin loop to participate in transcriptional regulation and also at the scale of the 270 nucleosome [11,70,71]. For example, plant-specific Agenet Domain Containing 271 Protein 1 (ADCP1) has recently been shown to drive the phase separation of 272 H3K9me3-marked nucleosome arrays to form condensates [72]. Such a mechanism 273 might be employed in the rice nucleoplasm to create physical contacts between 274 multiple heterochromatin loci, which was revealed by a ChIA-PET study [35]. For 275 example, nucleosome arrays behave like LLPS, with histone tail and linker histone $\mathrm{H} 1$ 276 playing a substantial role in their level of compaction [73]. Interestingly, histone tail 277 acetylation seems to be able to regulate LLPS of nucleosome arrays [74]. Another 278 example is with the clustering of RNA polymerase II, which is due to LLPS mediated 279 by the presence of IDRs in its C-terminal domain [75]. Furthermore, droplets generated 280 via LLPS can potentially act as mechano-active chromatin filters. Most IDR-containing 281 proteins indeed exclude chromatin, which explain why nuclear bodies usually display 282 a low chromatin density. This mechanism facilitate chromatin factors to target genomic 283 loci by changing their concentration in a given compartment [76] (Wei et al. 2019). For 284 example, the MEDIATOR complex subunit MED1 was shown to form nuclear puncta 285 at enhancers, concentrating RNA polymerase II to achieve desired expression levels 286 at target loci [77].

287 IDRs are usually composed of Arginine/Glycine (R/G) rich and/or 288 Glutamine/Asparagine $(\mathrm{Q} / \mathrm{N})$ rich domains [78,79]. One of the best-studied cases of 
289 IDRs-mediated LLPS is the nucleolus [80]. In mammal cells, the R/G-rich domains of

290 the nucleolar proteins nucleoplasmin and fibrillarin were both shown to be required for

291 the formation of the nucleolus, as well as for the sub-nucleolar compartments [81]. In

292 plants, there is no homolog of nucleoplasmin, but FIBRILLARIN 2 (FIB2), NUCLEOLIN

2931 (NUC1), and many other nucleolar proteins possess strong IDRs (Figure 3). Thus,

294 potential LLPS driven by these nucleolar proteins might be crucial for forming

295 functional plant nucleoli. This hypothesis is supported by the fact that NUC1 disruption

296 leads to the nucleolus disorganization $[82,83]$.

Arabidopsis thaliana proteins with IDRs

299 Although the plant science community is aware of the potential importance of LLPS in 300 shaping chromatin domains, there are few examples described in plants so far [15,84]. 301 We therefore attempted to search for $A$. thaliana proteins containing IDRs with R/G302 rich and/or $\mathrm{Q} / \mathrm{N}$-rich stretches (Figure 3a). Amongst the 27416 proteins encoded by 303 the $A$. thaliana genome, $1234 \mathrm{R} / \mathrm{G}$-rich and/or Q/N-rich IDR-containing proteins were 304 identified (Supplemental Table 1). Interestingly, there are only 4 proteins that have 305 both types of IDR motifs (Figure 3b). The 51 proteins containing at least 4 GGRG 306 motifs are implicated in the RNA metabolism (GO:0016070; $p$ value 3.5E-3) and are 307 found in nuclear bodies like the nucleolus, nuclear speckles, photobodies or Cajal 308 bodies (Figure 3a) (Love et al. 2017; Zhu and Brangwynne 2015; Montacie et al. 2017; $309 \mathrm{Li}$ et al. 2019). This list is also composed of proteins known to localize in cytoplasmic 310 bodies like processing bodies and stress granules (e.g., DCP5 and AGO1).

311 Among the 80 proteins containing a long $\mathrm{Q} / \mathrm{N}$-rich stretch (at least $40 \mathrm{Q} / \mathrm{N}$ residues), 312 half of them are implicated in transcriptional regulation (GO: 0006355; $p$ value 1.05E313 14). Notably, a member of this list, FCA, is involved in LLPS and required for proper 314 transcriptional termination [85]. Our screen also identified a strong Q/N-rich IDR in 315 NERD, a nuclear protein implicated in the 3' end formation of another subset of mRNAs 316 [86]. In this case, proper mRNA termination requires both NERD and FIP37-dependent 317 N6-adenosine mRNA methylation [86]. The fact that NERD forms nuclear foci through 318 LLPS remains to be investigated. Additionally, we observed many transcription factors 319 (e.g., MADS-box proteins) and mediators in this list (Figure 3a). MADS-box proteins 320 have been long known for mediating chromatin looping via forming protein complexes 321 [87,88]. MED25, which contains an extraordinarily strong Q/N-rich stretch, has been 322 recently shown to be required for establishing chromatin contacts between enhancers 
323 and target genes in the jasmonate signaling pathway in plants [89]. Although our IDR-

324 containing protein list implies an existing 3D interaction network functioning in 325 transcriptional regulation (e.g., promoter-promoter interactions and cooperative 326 transcription), the functional implication of these $\mathrm{Q} / \mathrm{N}$-rich stretches remains to be 327 evidenced in plants. A systematic analysis of the nuclear localization of plant IDRs 328 should lead to the discovery of proteins implicated in LLPS-dependent nuclear puncta 329 formation.

$331 \quad$ Perspectives

332 Recent advances have greatly helped scientists better understand the mechanisms by 333 which chromatin domains are brought together in 3D. It is noteworthy that the list of 334 chromatin organization regulators is expanding rapidly. Recent work from Xiang-Dong $335 \mathrm{Fu}$ and colleagues revealed the presence of a large, unexpected subset of RNA336 binding proteins at numerous chromatin sites [90]. As many RNA-interacting proteins 337 are implicated in LLPS, it is reasonable to speculate that some of them may regulate 338 chromatin looping and compartmentalization. This study also gives us a hint that the 339 interactions between RNA-binding proteins and chromatin in plants might have been 340 unsuspected.

341 As discussed earlier, there is a correlation between chromatin domains and their local 342 epigenetic signatures. In addition, to assess the transcriptional regulation of a given 343 gene, it is essential to identify all the direct and indirect interacting-factors of the gene, 344 i.e., the other genomic regions, RNA, and proteins [57]. Moreover, the supra-molecular 345 arrangements created by LLPS also seem to play a role in protein regulation via their 346 retention as demonstrated for the DNA methyltransferase DNMT1, retained in the 347 nucleolus during acidosis in human cells (Audas et al 2012). With the growing evidence 348 in animal models (Zhu and Brangwynne, 2015), LLPS processes are likely to play an 349 equally important role in the organization of plant chromatin and its partitioning into 350 functional, spatially separated domains. In animal cells, high-to-super resolution 351 techniques have led to a better understanding of the 3D chromatin domain analyses 352 (Shin Y et al, 2018; Wei et al, 2019; (Szabo et al. 2018). Although important progress 353 have been made, plant cells specificity makes the use of these techniques more 354 challenging (Dumur et al 2019). 
357 The authors declare no conflict of interest.

\section{Acknowledgements}

360 We apologize to authors whose work could not be cited due to space constraint. The 361 authors thank Moaine El baidouri and Ariadna Picart-Picolo for their input. F.P. was 362 supported by the French Laboratory of Excellence project TULIP (ANR-10-LABX-41 363 and ANR-11-IDEX-0002-02), the ANR NucleoReg (ANR-15-CE12-0013-01). C.L. was 364 supported by the European Research Council (ERC) under the European Union's 365 Horizon 2020 research and innovation programme (grant agreement No. 757600). C.L. 366 and F.P. are part of the COST ACTION CA16212 INDEPTH.

\section{References and recommended reading}

369 Papers of particular interest, published within the period of review, have been 370 highlighted as: 
References:

376

377

378

379

380

381

382

383

384

385

386

387

388

389

390

391

392

393

394

395

396

397

398

399

400

401

402

403

404

405

406

407

408

409

410

411

412

413

414

415

416

417

418

419

1. Kouzarides T: Chromatin modifications and their function. Cell 2007, 128:693-705.

2. Rowley MJ, Corces VG: Organizational principles of 3D genome architecture. Nat Rev Genet 2018, 19:789-800.

3. Mao YS, Zhang B, Spector DL: Biogenesis and function of nuclear bodies. Trends Genet 2011, 27:295-306.

4. Guelen L, Pagie L, Brasset E, Meuleman W, Faza MB, Talhout W, Eussen BH, de Klein A, Wessels L, de Laat W, et al.: Domain organization of human chromosomes revealed by mapping of nuclear lamina interactions. Nature 2008, 453:948-951.

5. van Koningsbruggen S, Gierlinski M, Schofield P, Martin D, Barton GJ, Ariyurek Y, den Dunnen JT, Lamond AI: High-resolution whole-genome sequencing reveals that specific chromatin domains from most human chromosomes associate with nucleoli. Mol Biol Cell 2010, 21:3735-3748.

6. Nemeth A, Conesa A, Santoyo-Lopez J, Medina I, Montaner D, Peterfia B, Solovei I, Cremer T, Dopazo J, Langst G: Initial genomics of the human nucleolus. PLoS Genet 2010, 6:e1000889.

7. Sexton T, Yaffe E, Kenigsberg E, Bantignies F, Leblanc B, Hoichman M, Parrinello H, Tanay A, Cavalli G: Three-dimensional folding and functional organization principles of the Drosophila genome. Cell 2012, 148:458-472.

8. Kaiserli E, Perrella G, Davidson ML: Light and temperature shape nuclear architecture and gene expression. Curr Opin Plant Biol 2018, 45:103111.

9. Bourbousse C, Mestiri I, Zabulon G, Bourge M, Formiggini F, Koini MA, Brown SC, Fransz P, Bowler C, Barneche F: Light signaling controls nuclear architecture reorganization during seedling establishment. Proc Natl Acad Sci U S A 2015, 112:E2836-2844.

10. Misteli T: Protein dynamics: implications for nuclear architecture and gene expression. Science 2001, 291:843-847.

11. Erdel F, Rippe K: Formation of Chromatin Subcompartments by Phase Separation. Biophys J 2018, 114:2262-2270.

12. Shin Y, Brangwynne CP: Liquid phase condensation in cell physiology and disease. Science 2017, 357.

13. Lieberman-Aiden E, van Berkum NL, Williams L, Imakaev M, Ragoczy T, Telling A, Amit I, Lajoie BR, Sabo PJ, Dorschner MO, et al.: Comprehensive mapping of long-range interactions reveals folding principles of the human genome. Science 2009, 326:289-293.

14. Dekker J, Belmont AS, Guttman M, Leshyk VO, Lis JT, Lomvardas S, Mirny LA, O'Shea CC, Park PJ, Ren B, et al.: The 4D nucleome project. Nature 2017, 549:219-226.

15. Stam M, Tark-Dame M, Fransz P: 3D genome organization: a role for phase separation and loop extrusion? Curr Opin Plant Biol 2019, 48:36-46. 
16. Sotelo-Silveira M, Chavez Montes RA, Sotelo-Silveira JR, Marsch-Martinez N, de Folter S: Entering the Next Dimension: Plant Genomes in 3D. Trends Plant Sci 2018, 23:598-612.

17. Dogan ES, Liu C: Three-dimensional chromatin packing and positioning of plant genomes. Nat Plants 2018, 4:521-529.

18. Zhu B, Zhang W, Zhang T, Liu B, Jiang J: Genome-Wide Prediction and Validation of Intergenic Enhancers in Arabidopsis Using Open Chromatin Signatures. Plant Cell 2015, 27:2415-2426.

19. Wu Z, Tang J, Zhuo J, Tian Y, Zhao F, Li Z, Yan Y, Yang R: Chromatin Signature and Transcription Factor Binding Provide a Predictive Basis for Understanding Plant Gene Expression. Plant Cell Physiol 2019.

20. Yan W, Chen D, Schumacher J, Durantini D, Engelhorn J, Chen M, Carles CC, Kaufmann K: Dynamic control of enhancer activity drives stagespecific gene expression during flower morphogenesis. Nat Commun 2019, 10:1705.

21. Sijacic P, Bajic M, McKinney EC, Meagher RB, Deal RB: Changes in chromatin accessibility between Arabidopsis stem cells and mesophyll cells illuminate cell type-specific transcription factor networks. Plant J 2018, 94:215-231.

22. Maher KA, Bajic M, Kajala K, Reynoso M, Pauluzzi G, West DA, Zumstein K, Woodhouse M, Bubb K, Dorrity MW, et al.: Profiling of Accessible Chromatin Regions across Multiple Plant Species and Cell Types Reveals Common Gene Regulatory Principles and New Control Modules. Plant Cell 2018, 30:15-36.

23. Sun J, He N, Niu L, Huang Y, Shen W, Zhang Y, Li L, Hou C: Global Quantitative Mapping of Enhancers in Rice by STARR-seq. Genomics Proteomics Bioinformatics 2019.

24. Zhang W, Wu Y, Schnable JC, Zeng Z, Freeling M, Crawford GE, Jiang J: Highresolution mapping of open chromatin in the rice genome. Genome Res 2012, 22:151-162.

25. Qiu Z, Li R, Zhang S, Wang K, Xu M, Li J, Du Y, Yu H, Cui X: Identification of Regulatory DNA Elements Using Genome-wide Mapping of DNase I Hypersensitive Sites during Tomato Fruit Development. Mol Plant 2016, 9:1168-1182.

26. Oka R, Zicola J, Weber B, Anderson SN, Hodgman C, Gent JI, Wesselink JJ, Springer NM, Hoefsloot HCJ, Turck F, et al.: Genome-wide mapping of transcriptional enhancer candidates using DNA and chromatin features in maize. Genome Biol 2017, 18:137.

27. Li Z, Wang M, Lin K, Xie Y, Guo J, Ye L, Zhuang Y, Teng W, Ran X, Tong Y, et al.: The bread wheat epigenomic map reveals distinct chromatin architectural and evolutionary features of functional genetic elements. Genome Biol 2019, 20:139.

28. Liu C, Wang C, Wang G, Becker C, Zaidem M, Weigel D: Genome-wide analysis of chromatin packing in Arabidopsis thaliana at single-gene resolution. Genome Res 2016, 26:1057-1068.

29. Dong Q, Li N, Li X, Yuan Z, Xie D, Wang X, Li J, Yu Y, Wang J, Ding B, et al.: Genome-wide $\mathrm{Hi}-\mathrm{C}$ analysis reveals extensive hierarchical chromatin interactions in rice. Plant J 2018, 94:1141-1156. 
30. Wang M, Tu L, Lin M, Lin Z, Wang P, Yang Q, Ye Z, Shen C, Li J, Zhang L, et al.: Asymmetric subgenome selection and cis-regulatory divergence during cotton domestication. Nat Genet 2017, 49:579-587.

31. Mumbach MR, Rubin AJ, Flynn RA, Dai C, Khavari PA, Greenleaf WJ, Chang HY: HiChIP: efficient and sensitive analysis of protein-directed genome architecture. Nat Methods 2016, 13:919-922.

32. Li G, Fullwood MJ, Xu H, Mulawadi FH, Velkov S, Vega V, Ariyaratne PN, Mohamed YB, Ooi HS, Tennakoon C, et al.: ChIA-PET tool for comprehensive chromatin interaction analysis with paired-end tag sequencing. Genome Biol 2010, 11:R22.

33. Li E, Liu H, Huang L, Zhang X, Dong X, Song W, Zhao H, Lai J: Long-range interactions between proximal and distal regulatory regions in maize. Nat Commun 2019, 10:2633.

34. Peng Y, Xiong D, Zhao L, Ouyang W, Wang S, Sun J, Zhang Q, Guan P, Xie L, Li $\mathrm{W}$, et al.: Chromatin interaction maps reveal genetic regulation for quantitative traits in maize. Nat Commun 2019, 10:2632.

35. Zhao L, Wang S, Cao Z, Ouyang W, Zhang Q, Xie L, Zheng R, Guo M, Ma M, Hu Z, et al.: Chromatin loops associated with active genes and heterochromatin shape rice genome architecture for transcriptional regulation. Nat Commun 2019, 10:3640.

36. Bersaglieri C, Santoro R: Genome Organization in and around the Nucleolus. Cells 2019, 8.

37. van Steensel B, Belmont AS: Lamina-Associated Domains: Links with Chromosome Architecture, Heterochromatin, and Gene Repression. Cell 2017, 169:780-791.

38. Bi X, Cheng YJ, Hu B, Ma X, Wu R, Wang JW, Liu C: Nonrandom domain organization of the Arabidopsis genome at the nuclear periphery. Genome Res 2017, 27:1162-1173.

39. Hu B, Wang N, Bi X, Karaaslan ES, Weber AL, Zhu W, Berendzen KW, Liu C: Plant lamin-like proteins mediate chromatin tethering at the nuclear periphery. Genome Biol 2019, 20:87.

40. Poulet A, Duc C, Voisin M, Desset S, Tutois S, Vanrobays E, Benoit M, Evans DE, Probst AV, Tatout C: The LINC complex contributes to heterochromatin organisation and transcriptional gene silencing in plants. J Cell Sci 2017, 130:590-601.

41. Pontvianne F, Carpentier MC, Durut N, Pavlistova V, Jaske K, Schorova S, Parrinello H, Rohmer M, Pikaard CS, Fojtova M, et al.: Identification of Nucleolus-Associated Chromatin Domains Reveals a Role for the Nucleolus in 3D Organization of the A. thaliana Genome. Cell Rep 2016, 16:1574-1587.

42. Carpentier MC, Picart-Picolo A, Pontvianne F: A Method to Identify Nucleolus-Associated Chromatin Domains (NADs). Methods Mol Biol 2018, 1675:99-109.

43. Kalinina NO, Makarova S, Makhotenko A, Love AJ, Taliansky M: The Multiple Functions of the Nucleolus in Plant Development, Disease and Stress Responses. Front Plant Sci 2018, 9:132.

44. Mikulski P, Hohenstatt ML, Farrona S, Smaczniak C, Stahl Y, Kalyanikrishna, Kaufmann K, Angenent G, Schubert D: The Chromatin-Associated 
Protein PW01 Interacts with Plant Nuclear Lamin-like Components to Regulate Nuclear Size. Plant Cell 2019, 31:1141-1154.

45. Groves NR, Biel AM, Newman-Griffis AH, Meier I: Dynamic Changes in Plant Nuclear Organization in Response to Environmental and Developmental Signals. Plant Physiol 2018, 176:230-241.

46. Meier I, Richards EJ, Evans DE: Cell Biology of the Plant Nucleus. Annu Rev Plant Biol 2017, 68:139-172.

47. Picart-Picolo A, Picault N, Pontvianne F: Ribosomal RNA genes shape chromatin domains associating with the nucleolus. Nucleus 2019, 10:67-72.

48. Fricker M, Hollinshead M, White N, Vaux D: Interphase nuclei of many mammalian cell types contain deep, dynamic, tubular membranebound invaginations of the nuclear envelope. J Cell Biol 1997, 136:531-544.

49. Vertii A, Ou J, Yu J, Yan A, Pages H, Liu H, Zhu LJ, Kaufman PD: Two contrasting classes of nucleolus-associated domains in mouse fibroblast heterochromatin. Genome Res 2019.

50. Simon L, Voisin M, Tatout C, Probst AV: Structure and Function of Centromeric and Pericentromeric Heterochromatin in Arabidopsis thaliana. Front Plant Sci 2015, 6:1049.

51. Dong P, Tu X, Chu PY, Lu P, Zhu N, Grierson D, Du B, Li P, Zhong S: 3D Chromatin Architecture of Large Plant Genomes Determined by Local A/B Compartments. Mol Plant 2017, 10:1497-1509.

52. Williams EJ, Bowles DJ: Coexpression of neighboring genes in the genome of Arabidopsis thaliana. Genome Res 2004, 14:1060-1067.

53. Ren XY, Stiekema WJ, Nap JP: Local coexpression domains in the genome of rice show no microsynteny with Arabidopsis domains. Plant Mol Biol 2007, 65:205-217.

54. Krom N, Ramakrishna W: Comparative analysis of divergent and convergent gene pairs and their expression patterns in rice, Arabidopsis, and populus. Plant Physiol 2008, 147:1763-1773.

55. Reimegard J, Kundu S, Pendle A, Irish VF, Shaw P, Nakayama N, Sundstrom JF, Emanuelsson O: Genome-wide identification of physically clustered genes suggests chromatin-level co-regulation in male reproductive development in Arabidopsis thaliana. Nucleic Acids Res 2017, 45:32533265.

56. Fudenberg G, Mirny LA: Higher-order chromatin structure: bridging physics and biology. Curr Opin Genet Dev 2012, 22:115-124.

57. Silveira MAD, Bilodeau S: Defining the Transcriptional Ecosystem. Mol Cell 2018, 72:920-924.

58. Nutzmann HW, Huang A, Osbourn A: Plant metabolic clusters - from genetics to genomics. New Phytol 2016, 211:771-789.

59. Nutzmann HW, Scazzocchio C, Osbourn A: Metabolic Gene Clusters in Eukaryotes. Annu Rev Genet 2018, 52:159-183.

60. Rhind N, Gilbert DM: DNA replication timing. Cold Spring Harb Perspect Biol 2013, 5:a010132.

61. Bass HW, Hoffman GG, Lee TJ, Wear EE, Joseph SR, Allen GC, Hanley-Bowdoin L, Thompson WF: Defining multiple, distinct, and shared spatiotemporal patterns of DNA replication and endoreduplication 
from 3D image analysis of developing maize (Zea mays L.) root tip nuclei. Plant Mol Biol 2015, 89:339-351.

62. Wear EE, Song J, Zynda GJ, LeBlanc C, Lee TJ, Mickelson-Young L, Concia L, Mulvaney P, Szymanski ES, Allen GC, et al.: Genomic Analysis of the DNA Replication Timing Program during Mitotic $S$ Phase in Maize (Zea mays) Root Tips. Plant Cell 2017, 29:2126-2149.

63. Concia L, Brooks AM, Wheeler E, Zynda GJ, Wear EE, LeBlanc C, Song J, Lee TJ, Pascuzzi PE, Martienssen RA, et al.: Genome-Wide Analysis of the Arabidopsis Replication Timing Program. Plant Physiol 2018, 176:2166-2185.

64. Lee TJ, Pascuzzi PE, Settlage SB, Shultz RW, Tanurdzic M, Rabinowicz PD, Menges M, Zheng P, Main D, Murray JA, et al.: Arabidopsis thaliana chromosome 4 replicates in two phases that correlate with chromatin state. PLoS Genet 2010, 6:e1000982.

65. Yokoyama R, Hirakawa T, Hayashi S, Sakamoto T, Matsunaga S: Dynamics of plant DNA replication based on PCNA visualization. Sci Rep 2016, 6:29657.

66. Sequeira-Mendes J, Vergara Z, Peiro R, Morata J, Araguez I, Costas C, MendezGiraldez R, Casacuberta JM, Bastolla U, Gutierrez C: Differences in firing efficiency, chromatin, and transcription underlie the developmental plasticity of the Arabidopsis DNA replication origins. Genome Res 2019, 29:784-797.

67. Sima J, Chakraborty A, Dileep V, Michalski M, Klein KN, Holcomb NP, Turner JL, Paulsen MT, Rivera-Mulia JC, Trevilla-Garcia C, et al.: Identifying cis Elements for Spatiotemporal Control of Mammalian DNA Replication. Cell 2019, 176:816-830 e818.

68. Joubes J, Chevalier C: Endoreduplication in higher plants. Plant Mol Biol 2000, 43:735-745.

69. Chevalier C, Bourdon M, Pirrello J, Cheniclet C, Gevaudant F, Frangne N: Endoreduplication and fruit growth in tomato: evidence in favour of the karyoplasmic ratio theory. J Exp Bot 2014, 65:2731-2746.

70. Sawyer IA, Bartek J, Dundr M: Phase separated microenvironments inside the cell nucleus are linked to disease and regulate epigenetic state, transcription and RNA processing. Seminars in Cell \& Developmental Biology 2019, 90:94-103.

71. Vaillant C, Jost DT: Modeling the Functional Coupling between 3D Chromatin Organization and Epigenome. 2019.

72. Zhao S, Cheng L, Gao Y, Zhang B, Zheng X, Wang L, Li P, Sun Q, Li H: Plant HP1 protein ADCP1 links multivalent $\mathrm{H} 3 \mathrm{~K} 9$ methylation readout to heterochromatin formation. Cell Res 2019, 29:54-66.

73. Turner AL, Watson M, Wilkins OG, Cato L, Travers A, Thomas JO, Stott K: Highly disordered histone H1-DNA model complexes and their condensates. Proc Natl Acad Sci U S A 2018, 115:11964-11969.

74. Gibson BA, Doolittle LK, Schneider MWG, Jensen LE, Gamarra N, Henry L, Gerlich DW, Redding S, Rosen MK: Organization of Chromatin by Intrinsic and Regulated Phase Separation. Cell 2019, 179:470-484 e421.

75. Boehning M, Dugast-Darzacq C, Rankovic M, Hansen AS, Yu T, Marie-Nelly H, McSwiggen DT, Kokic G, Dailey GM, Cramer P, et al.: RNA polymerase II 
clustering through carboxy-terminal domain phase separation. Nature Structural \& Molecular Biology 2018, 25:833-+.

76. Shin Y, Chang YC, Lee DSW, Berry J, Sanders DW, Ronceray P, Wingreen NS, Haataja M, Brangwynne CP: Liquid Nuclear Condensates Mechanically Sense and Restructure the Genome. Cell 2018, 175:1481-1491 e1413.

77. Sabari BR, Dall'Agnese A, Boija A, Klein IA, Coffey EL, Shrinivas K, Abraham BJ, Hannett NM, Zamudio AV, Manteiga JC, et al.: Coactivator condensation at super-enhancers links phase separation and gene control. Science 2018, 361.

78. Boeynaems S, Alberti S, Fawzi NL, Mittag T, Polymenidou M, Rousseau F, Schymkowitz J, Shorter J, Wolozin B, Van den Bosch L, et al.: Protein Phase Separation: A New Phase in Cell Biology. Trends in Cell Biology 2018, 28:420-435.

79. Bergeron-Sandoval LP, Safaee N, Michnick SW: Mechanisms and Consequences of Macromolecular Phase Separation. Cell 2016, 165:1067-1079.

80. Brangwynne CP, Mitchison TJ, Hyman AA: Active liquid-like behavior of nucleoli determines their size and shape in Xenopus laevis oocytes. Proceedings of the National Academy of Sciences of the United States of America 2011, 108:4334-4339.

81. Feric M, Vaidya N, Harmon TS, Mitrea DM, Zhu L, Richardson TM, Kriwacki RW, Pappu RV, Brangwynne CP: Coexisting Liquid Phases Underlie Nucleolar Subcompartments. Cell 2016, 165:1686-1697.

82. Pontvianne F, Matia I, Douet J, Tourmente S, Medina FJ, Echeverria M, SaezVasquez J: Characterization of AtNUC-L1 reveals a central role of nucleolin in nucleolus organization and silencing of AtNUC-L2 gene in Arabidopsis. Molecular Biology of the Cell 2007, 18:369-379.

83. Picart C, Pontvianne F: Plant nucleolar DNA: Green light shed on the role of Nucleolin in genome organization. Nucleus 2017, 8:11-16.

84. Wang N, Liu C: Implications of liquid-liquid phase separation in plant chromatin organization and transcriptional control. Curr Opin Genet Dev 2019, 55:59-65.

85. Fang X, Wang L, Ishikawa R, Li Y, Fiedler M, Liu F, Calder G, Rowan B, Weigel D, Li P, et al.: Arabidopsis FLL2 promotes liquid-liquid phase separation of polyadenylation complexes. Nature 2019, 569:265-269.

86. Pontier D, Picart C, El Baidouri M, Roudier F, Xu T, Lahmy S, Llauro C, Azevedo J, Laudie M, Attina A, et al.: The m(6)A pathway protects the transcriptome integrity by restricting RNA chimera formation in plants. Life Sci Alliance 2019, 2.

87. Theissen G, Saedler H: Plant biology. Floral quartets. Nature 2001, 409:469-471.

88. Melzer R, Verelst W, Theissen G: The class E floral homeotic protein SEPALLATA3 is sufficient to loop DNA in 'floral quartet'-like complexes in vitro. Nucleic Acids Res 2009, 37:144-157.

89. Wang H, Li S, Li Y, Xu Y, Wang Y, Zhang R, Sun W, Chen Q, Wang XJ, Li C, et al.: MED25 connects enhancer-promoter looping and MYC2-dependent activation of jasmonate signalling. Nat Plants 2019, 5:616-625. 
90. Xiao R, Chen JY, Liang ZY, Luo DJ, Chen G, Lu ZJ, Chen Y, Zhou B, Li HR, Du X, et al.: Pervasive Chromatin-RNA Binding Protein Interactions Enable RNA-Based Regulation of Transcription. Cell 2019, 178:107-+.

91. Fiserova J, Kiseleva E, Goldberg MW: Nuclear envelope and nuclear pore complex structure and organization in tobacco BY-2 cells. Plant J 2009, 59:243-255.

92. Ciska M, Hikida R, Masuda K, Moreno Diaz de la Espina S: Evolutionary history and structure of nuclear matrix constituent proteins, the plant analogues of lamins. J Exp Bot 2019, 70:2651-2664.

Li Q, Peng X, Li Y, Tang W, Zhu J, Huang J, Qi Y, Zhang Z. 2019. LLPSDB: a database of proteins undergoing liquid-liquid phase separation in vitro. Nucleic Acids Research. https://doi.org/10.1093/nar/gkz778 (Accessed November 8, 2019).

Love AJ, Yu C, Petukhova NV, Kalinina NO, Chen J, Taliansky ME. 2017. Cajal bodies and their role in plant stress and disease responses. RNA Biol 14: 779-790.

Montacie C, Durut N, Opsomer A, Palm D, Comella P, Picart C, Carpentier M-C, Pontvianne F, Carapito C, Schleiff E, et al. 2017. Nucleolar Proteome Analysis and Proteasomal Activity Assays Reveal a Link between Nucleolus and $26 \mathrm{~S}$ Proteasome in A. thaliana. Frontiers in plant science 8: 1815.

Zhu L, Brangwynne CP. 2015. Nuclear bodies: the emerging biophysics of nucleoplasmic phases. Curr Opin Cell Biol 34: 23-30.

Wei M-T, Chang Y-C, Shimobayashi SF, Shin Y, Brangwynne CP. 2019. Nucleated transcriptional condensates amplify gene expression. bioRxiv 737387.

Szabo Q, Jost D, Chang J-M, Cattoni DI, Papadopoulos GL, Bonev B, Sexton T, Gurgo J, Jacquier C, Nollmann M, et al. 2018. TADs are 3D structural units of higherorder chromosome organization in Drosophila. Sci Adv 4: eaar8082.

Dumur T, Duncan S, Graumann K, Desset S, Randall RS, Scheid OM, Prodanov D, Tatout C, Baroux C. 2019. Probing the 3D architecture of the plant nucleus with microscopy approaches: challenges and solutions. Nucleus 10: 181-212. 

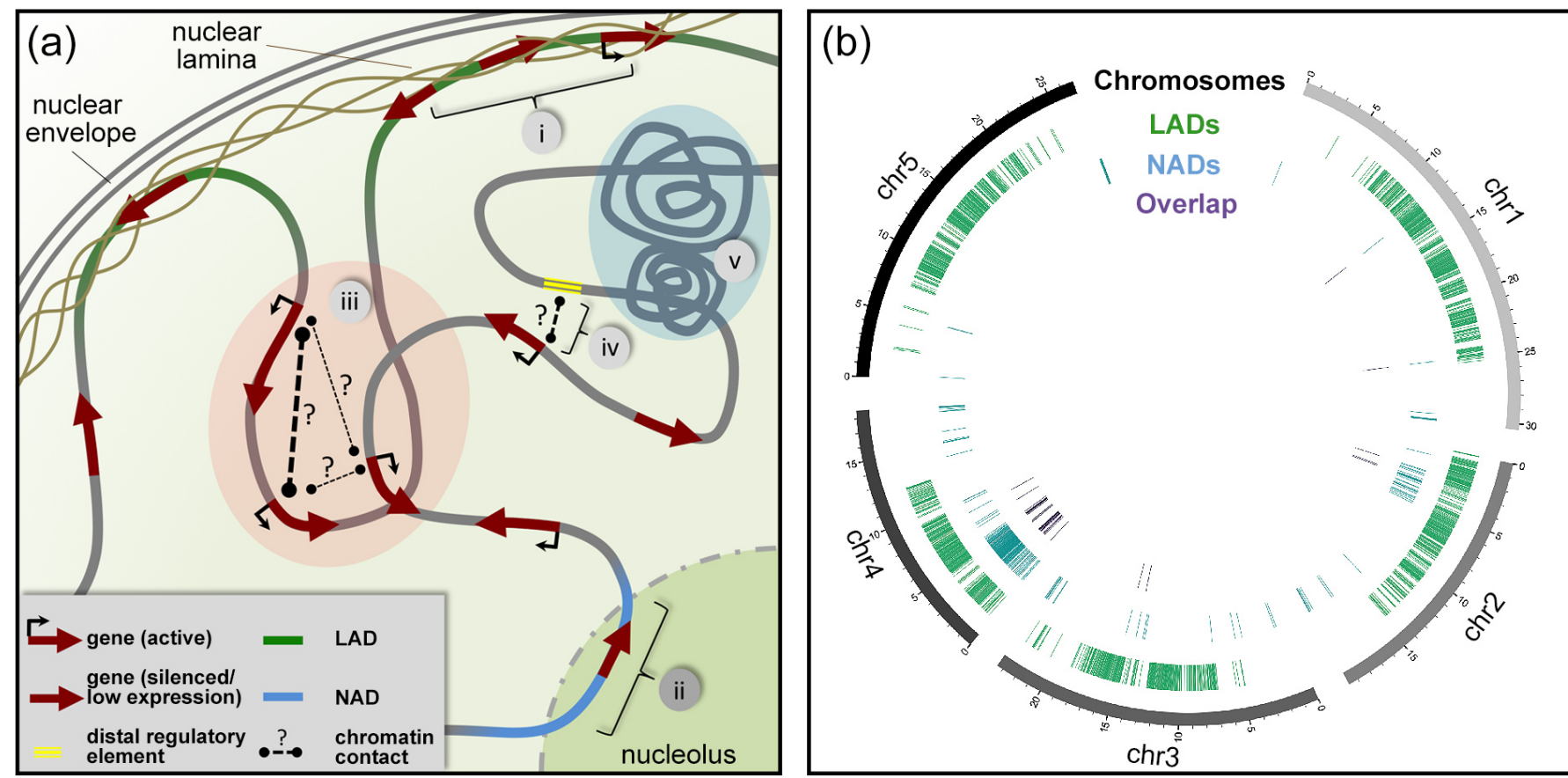

695 Figure 1. Spatial distribution of chromatin regions.

696 (a) A sketch illustrating spatial patterns of plant chromatin in the nucleus and their 697 association with gene expression. Note that plants do not encode lamin proteins. The

698 term "plant nuclear lamina" refers to filamentous protein structure that underlies the 699 inner nuclear membrane [91]. Plant nuclear lamina very likely consists of plant-specific 700 Nuclear Matrix Constituent Proteins (NMCP, also known as CRWN in Arabidopsis) 701 [92]. In general, chromatin regions located at the nuclear periphery (i) and at the 702 nucleolus (ii) tend to be inactive. Recent studies have revealed a large number of 703 chromatin contacts linking actively expressed gene with one another (iii), as well as 704 with distal regions having potential roles in transcriptional regulation (iv). The question 705 marks besides these chromatin contacts depict the current situation that little is known 706 about how the interactions are established. These chromatin contacts are established 707 by factor yet unknown (question marks), which we speculate to be combinatorial 708 activities of stochastic chromatin movements, specific bridging interactions of proteins 709 and RNAs, and liquid-liquid phase separation. The contacts among expressed genes 710 foster the formation of sub-compartments and coordinated transcription. Besides, 711 multiple H3K9me-marked loci can form puncta in the nucleoplasm (v), which is likely 712 driven by liquid-liquid phase separation mediated by plant-specific ADCP1 proteins 713 [72]. LAD, lamina-associate domains; NAD, nucleolus-associated domains. (b) 714 Location of LADs and NADs loci across the Arabidopsis genome. This circos plot is 715 generated based on domain coordinates described in [39] and [41]. 

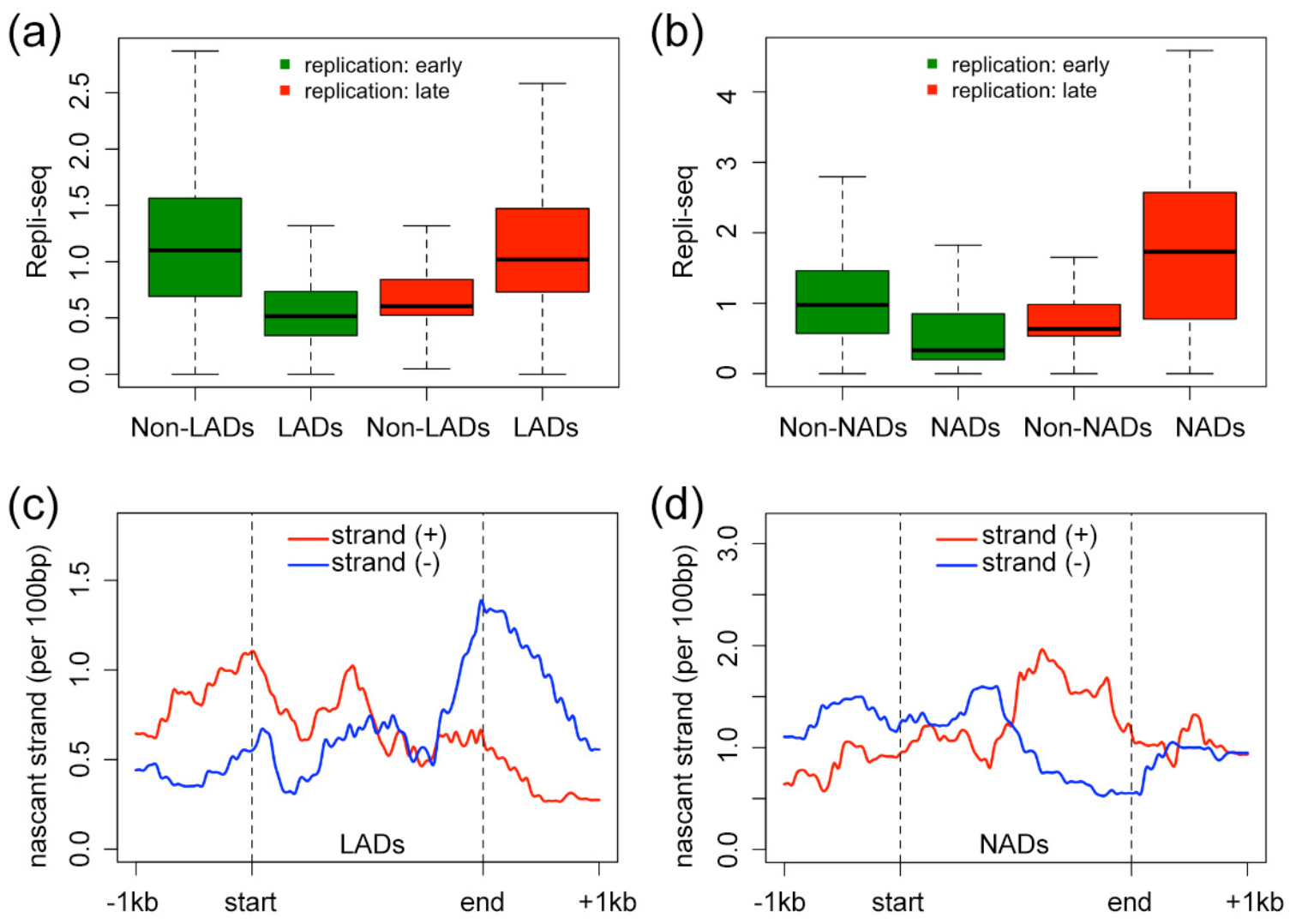

717 Figure 2. Association between DNA replication timing and chromatin localization 718 in Arabidopsis.

719 (a and b) Comparisons of Arabidopsis DNA replication activities (measured with Repli720 seq by Concia et al. [63]) in early and late S phase stages in LADs (a) and NADs (b). 721 (c and d) Distribution of leading nascent DNA strands in ORIs (DNA replication origin) 722 across LADs (c) and NADs (d). Note that the dataset describing nascent DNA strand 723 is from a study by Sequeira-Mendes et al. [66], in which a size cutoff ( 0.3 to $2 \mathrm{~kb}$ ) was 724 used so that the recovered nascent strands were primarily leading strands in ORIs. 725 This information, in turn, can be used to infer whether ORIs occur across a given 726 genomic region evenly. For instance, the curves in (c) imply that around LAD boundary 727 regions, ORIs fire more often outside LADs than inside. Plant materials used for 728 generating these datasets are partly comparable: Repli-seq, 7-day-old seedlings; 729 nascent DNA strands, 4-day-old and 10-day-old seedlings; LADs, 10-day-old 730 seedlings; and NADs, 3-week-old seedlings. Datasets and scripts for reproducing plots 731 in panels (a-d) are available from figshare repository with DOI: $73210.6084 / \mathrm{m} 9$.figshare.8953235. Before publication, these datasets and scripts are 733 accessible with this private link: https://figshare.com/s/e9ec0a926a1840e2455b 
(a)

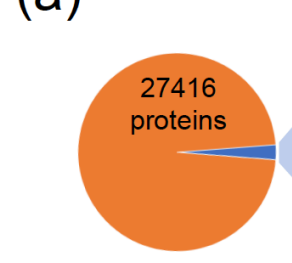

1234 proteins in $A$. thaliana with an R/G-
rich and/or a $Q / N-$
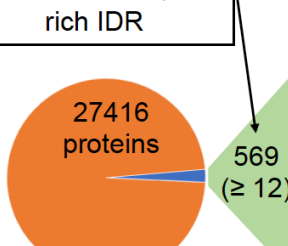

$\mathrm{Nb}$. of GGRG

R/G-rich IDRs
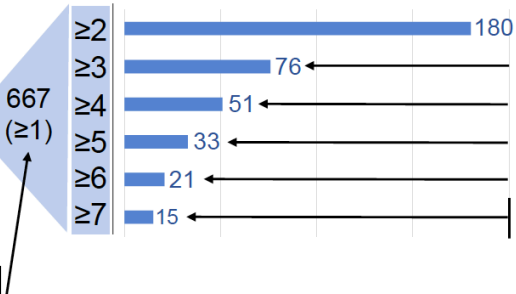

$\geq 4=51$

$\geq 5 \quad 33$

$\geq 6 \quad 21$

$\geq 7$
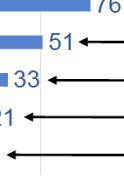

Q/N residues

$\geq 20$

$\geq 40$

$\geq 50$

$\geq 75$

$\geq 100$ (b)

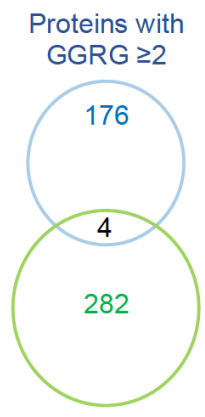

Proteins with $\mathrm{Q} / \mathrm{N}$ residues $\geq 20$ in an IDR

Figure 3. Identification of $A$. thaliana proteins containing an R/G-rich and/or a Q/N-rich IDR.

737 (a) Among the 27416 referenced proteins in the $A$. thaliana genome (TAIR10), 1234

738 possess at least a GGRG motif or a stretch of $\mathrm{Q} / \mathrm{N}$ (at least $12 \mathrm{Q}$ or $\mathrm{N}$ in 30 continuous

739 amino acids). The numbers of proteins with more GGRG motifs or stronger Q/N stretch

740 are presented. The key proteins are listed, and their respective subnuclear

741 compartment is specified in brackets. (b) Venn diagram demonstrating the lack of

742 overlap between proteins containing at least two R/G-rich and a strong Q/N-rich IDR.

743 Protein sequences were downloaded from TAIR10 https://www.arabidopsis.org/. The

744 identification of IDR-containing proteins was based on text mining with following

745 criteria: R/G motifs were called if they exactly matched text string "GGRG"; Q/N motifs

746 were called when at least $12 \mathrm{Q} / \mathrm{N}$ residues were found in a window of 30 amino acids.

747 Overlapping $\mathrm{Q} / \mathrm{N}$ motifs were further merged. For each IDR-containing protein, the

748 number of $R / G$ motifs and/or the number of $Q / N$ residues in IDR can be found in

749 Supplemental Table 1. 